\title{
Critically Reflective Work Behaviour Within Autonomous Professionals' Learning Communities
}

\author{
Esther de Groot • B. A. M. van den Berg • \\ M. D. Endedijk • P. van Beukelen • P. R. J. Simons
}

Received: 26 November 2009 / Accepted: 18 October 2010 /

Published online: 30 October 2010

(C) The Author(s) 2010. This article is published with open access at Springerlink.com

\begin{abstract}
Informal learning communities in which participants show critically reflective work behaviour (CRWB) have the potential to support lifelong learning. In practice this behaviour does not always occur in groups of autonomous professionals. This study explores design principles (DPs) that could act as social affordances for CRWB, within the context of healthcare professionals. From the literature, 28 DPs were deduced. In an online Delphi study, 12 experts gave their opinions about these. To explore strategies for implementation of these DPs, a faceto-face expert discussion meeting was organized. The Delphi study resulted in a subset of 13 DPs considered to be relevant for CRWB. Some of the design principles were confirmed or reformulated, others were considered to be unimportant. Exploration of strategies for implementation confirmed the importance of having moderators from within the group. The results of this study, combining issues of design and implementation, could contribute to the discussion about the support and set-up of learning communities for autonomous professionals. A framework for
\end{abstract}

E. de Groot ( $\square)$

Quality improvement in Veterinary Education, Faculty of Veterinary Medicine, Utrecht University, PO Box 80163, 3508 TD Utrecht, The Netherlands

e-mail: e.degroot@uu.nl

B. A. M. van den Berg $\cdot$ M. D. Endedijk $\cdot$ P. R. J. Simons

IVLOS Institute of Education, Utrecht University, PO Box 80127, 3508 TC Utrecht, The Netherlands

B. A. M. van den Berg

e-mail: B.A.M.vandenberg@uu.nl

M. D. Endedijk

e-mail: M.D.Endedijk@uu.nl

P. R. J. Simons

e-mail: P.R.J.Simons@uu.nl

P. van Beukelen

Faculty of Veterinary Medicine, Utrecht University, PO Box 80163, 3508 TD Utrecht, The

Netherlands

e-mail: p.vanbeukelen@uu.nl 
behavioural change is considered that could help to understand why these DPs should influence participants' interaction.

Keywords Critically reflective work behaviour - Learning communities · Workrelated learning $\cdot$ Design principles $\cdot$ Implementation $\cdot$ Delphi study

These days the workplace demands continuing professional development and learning throughout working lives since, in many domains, knowledge is developing at a rapid rate (Billett 2001; Simons and Ruijters 2004). The need for continuous development and maintenance of expertise also applies to autonomous healthcare professionals like general practitioners, veterinarians, pharmacists and dentists working in small and medium sized practices (Moore et al. 2000; Swanwick 2005), who often lack opportunities for face-to-face contact with colleagues on a daily basis. Keeping up with new developments in their field is essential, and awareness of the evidence for their clinical decisions is also a growing demand these professionals encounter, which is largely a result of the growing importance of Evidence Based Practice (EBP) in the medical professions (Sackett et al. 1996).

It has been argued, for example by Oxman et al. (1995), and Davis et al. (1999), that this lifelong learning is not supported very successfully by learning in formal settings. An alternative is to focus on informal learning communities (Eraut 2004), in which learning is more aligned with modern views on learning. Here, learning is no longer seen as an activity of the individual alone but takes place in social interaction (Price and Felix 2008; Brown and Campione 1996). These informal ways of learning are becoming increasingly common in literature on work-related learning (Hodkinson et al. 2008), and are presumably especially fitting for professionals in the medical field. They find lack of time a major barrier to participation in learning activities without a clear link to their daily practice (Bennett et al. 2000; Moore et al. 2000). Owing to their time constraints, meeting with other members of the community face-to-face and online alternately, called blended learning communities, could offer additional advantages for these professionals (Parboosingh 2002). Taking our departure from the idea that learning communities might add continuing education opportunities for autonomous professionals, we will in this study explore what is relevant for the design of those learning communities, when critically reflective behaviour within those groups is the desired result. As we go along in this exploration, we will inquire into possible implementation strategies for these design principles, given the tension between design, which suggests a top-down process, and informal learning among autonomous professionals, which is not sensitive to directives.

\section{Learning Communities}

Informal blended learning in communities, where engagement and personal passion for the domain are crucial (Wenger et al. 2002), is often regarded as attractive. Yet, the practice of different terminology in the literature about communities does not help to understand their possibilities for learning. In the educational literature and in 
literature on knowledge management, different words are employed for concepts that have many similarities, or the same word is applied for notions that have little in common (Cox 2005). Learning networks (Koper et al. 2005), learning communities (Ferguson et al. 2009; Wood 2007), knowledge communities (Hakkarainen et al. 2004), communities of practice (Wenger et al. 2002), peer meetings (Tigelaar et al. 2008) and critical companionship (Baguley and Brown 2009; Wright and Titchen 2003) appear for groups of different sizes, in different contexts like education and business, with or without explicit learning objectives. Nevertheless, most of these concepts encompass discussion among peers, with the purpose of sharing knowledge and constructing meaning socially. In this study, we use the term learning communities to place the learning purpose in the centre, in which we follow Wood (2007). She investigates groups of teachers who, in her words, "engage in collective inquiry in order to weigh their practices and innovations against empirical evidence and critical dialogue" (2007, p. 282). We consider learning communities to be small groups in which autonomous professionals, from different small enterprises, engage in discussions independently, without a master-apprentice relation. They share and create knowledge about their profession collaboratively, during face-to-face meetings as well as online meetings (a combination referred to as "blended"), without predefined targets, deliverables or returns expected.

\section{Critically Reflective Work Behaviour}

We argue that to benefit most from participation within informal learning communities, interaction within these communities needs to be critically reflective. Critical reflection is a concept with many faces. In the literature a large diversity of terminology is used to describe it, such as reflective judgment, critical thinking, reflection and reflective practice (Delany and Watkin 2009; Fook and Askeland 2007; King and Kitchener 2004; Mann et al. 2007; Maudsley and Strivens 2000; J. D. Mezirow 1990; J. Mezirow 1998; Schön 1991; ten Dam and Volman 2004). At the same time critical reflection is defined in at least two different ways. First, there is critical reflection with a purpose of emancipation, and empowerment with a focus on power relations within groups (Brookfield 2009; Karvinen-Niinikoski 2009; ten Dam and Volman 2004). Second, there is an interpretation where argumentation and challenging assumptions (J. D. Mezirow 1990; J. Mezirow 1998), in order to improve practice, are dominant. Although empowerment is an element in these last sources as well, the emphasis is more on "purposeful critical analysis of knowledge and experience, in order to achieve deeper meaning and understanding" (Mann et al. 2007, p. 597). We consider critical reflection for learning communities within this last view because within the context of autonomous professionals, given the growing interest in EBP, argumentation for improved practice is most relevant.

Apart from these differences, critical reflection may be approached from a cognitive, individualistic perspective or from a social perspective. We emphasize the latter in this study because we focus on learning communities. The focus is on learning from experience as a result of looking back together with other professionals of the same profession, through discourse about what happened in daily practice. Within this perspective, critical reflection is not an invisible process, occurring in the head, but 
behaviour within a group as a result of individual thinking and social interaction. As the point of departure we selected the concept of critically reflective work behaviour (CRWB) as described in the work of Van Woerkom (2003) and of Van Woerkom and Croon (2008). Van Woerkom's seven dimensions as indicators of CRWB have been developed in the setting of large business organizations. Because in our study the focus is on work-related learning in informal small groups of professionals, not all seven dimensions were applicable. We studied: challenging groupthink, critical opinion sharing, openness about mistakes, asking for feedback, and experimentation. Left out were the dimensions "career awareness" and "reflective working", as the first one applies mainly to an organizational context and the second, according to Van Woerkom (2003) is done outside the social interaction of a group. The dimension "challenging groupthink" is about criticizing espoused theories within a group: although all members agree on an idea, contrary ideas are analyzed. Groupthink occurs in groups where, according to Janis (1982, p. 9), "the members' striving for unanimity override their motivation to realistically appraise alternative courses of action". The risk of groupthink increases when a group of people is striving for consensus and unanimity (Cruz et al. 2006; Janis 1982; Klocke 2007). "Critical opinion sharing", the second dimension of CRWB, puts emphasis on a "constructive challenge intended to improve rather than merely criticize" (Van Woerkom and Croon 2008) and on proposing alternatives. The third dimension of CRWB is "openness about mistakes". Reflecting on mistakes is essential for correcting false assumptions, and a helpful start for exploration of alternatives. As such it has been viewed as a special form of experiential learning, highly relevant for professional learning (Gartmeier et al. 2008). According to Van Woerkom (2003), being able to learn from mistakes is not only an individual activity but an essential social activity. "Asking for feedback" is the fourth dimension of CRWB. Receiving feedback has often been regarded as a prerequisite for learning to occur (Hattie and Timperley 2007). For professionals, asking for feedback in their daily work demands special attention, especially when they work alone or in small practices (Ashford et al. 2003). Learning communities could add opportunities to ask for feedback. "Experimentation", the fifth dimension of CRWB, is treated by Van Woerkom as a broader concept for reflection-in-action (Schön 1991). As such it will probably not take place during the meetings of learning communities, but in the daily work setting. Nevertheless, talking about thought experiments and exploring and imagining alternatives could take place during discussion meetings (Kamin et al. 2003).

Critical reflection, through an exchange of knowledge between professionals including arguments and delving into assumptions, seldom arises spontaneously (Huysman and Wulf 2004; Earl and Timperley 2009). Research has shown for instance that in medical case conferences in face-to-face settings members often lack a scholarly attitude (Gambrill 1990; Kim et al. 2006). Moreover, the lack of critical reflection appears in the criticisms on the concept of communities of practice for instance. The relation between novices and experts holds a risk of conservatism when learning processes are limited to replication of experts' behaviour (Hakkarainen et al. 2004). In formal educational settings it has also proved difficult to realize critical and constructive online discussions (Janssen et al. 2007) even though the use of Information and Communication Technology (ICT) has been mentioned as an aid in making interaction within learning communities more critically reflective. Therefore, 
further exploration is needed to understand CRWB, and what might be done to transform groups of autonomous professionals in learning groups, without violating the informal character of their learning.

\section{Design Principles as Social Affordances}

To reach understanding of transformations towards more CRWB in learning groups, a design-based research approach was chosen, a method in which exploring how to bring about change in behaviour is essential. In design-based research, according to Gravemeijer and Cobb (2006), a well known adage is "If you want to understand something, you have to change it". When aiming for behavioural change towards more CRWB in learning communities we look at design principles in a nondeterministic way, which can be explained by describing the concept of social affordances. "Affordance" is a concept used primarily for technological environments, meaning that the shape of things leads the user to use it in a specific way (Billett and Pavlova 2005). Kirschner et al. (2004) use this concept in the context of interaction design, describing properties of the online collaborative learning environment which invite learners' social interaction. Gaver (1996) utilizes the concept without technical environments in mind; he describes affordances as possibilities for action that people offer one another. The significance of behaviour, by local interacting agents, for learning has been accorded attention recently by Johnsson and Boud (2010). This view of social affordances has guided us in our search for design principles (DPs), describing kinds of behaviour which serve as implicit invitations to and accelerators for CRWB within an informal learning community. In our search we emphasize domain-general aspects, which are relevant for most autonomous healthcare professionals, without disregarding the importance of domain-specific aspects (Hagler and Brem 2008).

\section{Implementing DPs}

Implementing these design principles as "implicit invitations" is not straightforward. In literature on communities a debate occurs about the evolution of the concept "learning community" ( $\mathrm{Li}$ et al. 2009). Perspectives vary between the idea that a learning community is run by the participants and as a consequence is barely designable (Wenger 1998), and the idea that communities can be cultivated and used as an instrument, for example in knowledge management (Wenger et al. 2002). Furthermore, little research has been done about the implementation of design in the context of autonomous professionals working in non or loosely coupled organizations. We expect that autonomous professionals will not be very sensitive to directives or willing to let others prescribe their way of interacting (Pinelle and Gutwin 2006). For example, the research of Akkerman et al. (2008), which was carried out in small practices, looks at characteristics of communities after their development, and does not pay attention to the process of development of the community itself. Therefore, we argue that defining design principles is not enough; investigating their implementation deserves more attention. 
In sum, our study is about beguiling autonomous professionals into CRWB within learning communities, because we expect that this behaviour will not take place automatically. Critically reflective work behaviour is not easy to evoke directly, but could be generated with social affordances described in design principles. It is intriguing to explore which principles are most relevant to facilitate CRWB, and how these affordances in a learning community need not be left to chance alone, but could be influenced by an external organization. These considerations and arguments lead us to three research questions:

1. What design principles (DPs), acting as social affordance(s) for CRWB within blended learning communities with autonomous professionals as members, can be abstracted from literature?

2. Which of these DPs are considered to be important by experts in the field of elearning, knowledge management and communities?

3. What strategies could an external organization employ to realize the DPs in blended learning communities, with autonomous professionals as members?

\section{Materials and Methods}

In order to answer the first research question we formulated design principles (DPs) based on studies in educational and organizational science. To find out about these principles' value and their relative importance (research question 2) an online Delphi survey was used. The third research question, about the DPs implementation, was approached by means of an expert discussion meeting.

\section{Literature Search}

To find out about ways to induce autonomous professionals to demonstrate CRWB, we undertook a literature search in several rounds, using the bibliographic database SCOPUS, restricting our search to articles published from 1990 to 2009, related to the appearance of literature about communities, with the exception of a core publication on groupthink by Janis (1982). We started with a preliminary search within the domain of work-related learning, using Van Woerkom's dimensions of CRWB as key terms. Consulting the literature this search provided, we derived the concept of self-efficacy that is expected to facilitate CRWB (Van Woerkom 2003). From the concept of self-efficacy we derived that the concepts motivation and trust had to be included as well. In the next round we searched SCOPUS, using these sensitizing concepts as key words. Next, articles were found using a snowball method, searching relevant articles cited in the first papers found and searching relevant articles cited in those. Furthermore, when relevant, forward citing (a functionality of SCOPUS) was used. In our search we focused on the context of selfsteering professionals, left out most of the literature on groups directed at decisionmaking and made use of literature on task-oriented teams only when it contained guidelines that we considered to be fitting for an informal setting. Finally, being interested in blended learning communities, we consulted the literature on collaborative online and blended learning. Our search resulted in a set of 38 articles. 
Presumed factors influencing CRWB, mediated by the aforementioned sensitizing concepts, were derived from the literature found and on this basis we formulated a set of DPs in terms of concrete behaviour of the participants within a learning community. For instance: when self-efficacy appeared to be an important condition for challenging groupthink, and social modelling emerged as a way to strengthen self-efficacy, we postulated that the guideline "Participants model for each other a critical and exploratory discussion style" would function as an affordance for CRWB. When saturation of the literature search was reached we discussed our list of DPs among four researchers authoring this study, eliminating overlap. Furthermore we had five researchers not involved in this study test the resulting DPs for wording and items causing confusion.

\section{Delphi Study}

Our next step was to explore the extent to which experts endorsed the DPs we had formulated. To this end an online Delphi study was adopted, for which we invited 14 experts in the field of e-learning, knowledge management and learning communities. The Delphi technique allows for anonymity of the respondents. Furthermore, the participants do not have insight into the answers of the other respondents, minimizing groupthink. The experts we selected according to the following line of reasoning. After having studied the literature, we concluded that a multidisciplinary perspective was important for the composition of the group of experts who would be rating our design principles, and a variety of insights had to be included. Therefore, a group of international experts with different theoretical and professional backgrounds was invited to participate. Five experts were experienced in the area of communities, two in critical reflection, four in e-learning and four in knowledge management (two experts were classified within two areas). Their area of expertise had been demonstrated by international publications, some of which had been part of our literature study. Following Sharkey and Sharples (2001), we undertook two rounds, avoiding participant fatigue and counting on achievement of stability after two rounds. We conducted the Delphi study over the internet, using an online questionnaire. The experts were invited by e-mail. After agreeing to participate they received an email with information about the research, an instruction and a link to the survey. A reminder was sent once during the first round and twice during the second round. The Delphi study took 46 days: 15 days for the first round and 16 days for the second round, with 15 days in between to analyze the first round.

Participants were asked to rate the relevance of the DPs for a learning community for homogeneous autonomous professionals on a four-point scale (4 very relevant, 3 relevant, 2 hardly relevant, 1 not relevant) and could choose the option "unknown to me", to be used when experts thought they lacked the expertise to rate that DP. An overview of the design principles which the participants were asked to rate can be found in Table 1. After each principle participants were asked to comment on their answer. What was the argumentation behind their opinion? What evidence was supporting it? What did they think about the phrasing of the principle or what was missing in this principle? In the principle on diversity we asked the experts in the first round an open question about what kind of diversity they thought would be most important in relation to CRWB, as groups can be diverse in many ways 
(expertise, gender, age). After the first round we utilized "diversity of expertise" only, as had been indicated by one of the participants in the first round. In addition a question about the implementation of each principle was asked in the first round. None of the questions was compulsory.

In the first round 14 experts agreed to participate, two of whom dropped out before the first round, resulting in 12 respondents. In the second round nine experts from the first round participated again, three dropped out and the two experts who had dropped out before the first round did participate in this second round, resulting in 11 respondents. To check whether these two new participants answered differently, we analyzed the answers of the experts who participated in the second round but not in the first round. Answers in the second round from both these experts were comparable to the answers from other respondents in the second round. Therefore we decided to include their answers in the analysis of the data from the second round. The experts' reasons for dropping out in either of the rounds are unknown. Not all open questions were answered (comment field), some respondents indicating that time pressure prevented them from answering these.

\section{Expert Discussion Meeting}

Strategies for implementation of the DPs were the subject of questions in the first round of the Delphi study, and explored further in a face-to-face expert discussion meeting. All five participants in the discussion meeting were involved in research on learning communities or online support of groups, carrying out empirical research themselves and implementing educational designs at national level. Several days beforehand they received a brief information letter about the research and goals of the discussion meeting in order to save as much time as possible during the one and a half hour discussion session. In the information letter we explained that we understood learning communities to be small homogeneous groups of professionals where interaction takes place partially face-to-face and partially online. We selected such a broad definition because we did not want to curtail their thoughts and ideas too much. The discussion meeting started with a short introduction and an overview of the DPs resulting from the Delphi survey. Participants were split into two subgroups which discussed possible interventions and presented their findings to each other. The central theme of the meeting was the question: given the set of prioritized DPs that resulted from the Delphi study, what can be done to implement these DPs in an informal learning community of autonomous professionals?

\section{Analysis}

For the analysis of the Delphi rounds we focused on the rating of the importance of the DPs. An impression of the importance of every DP is expressed by the mean of the items. The mean tells us whether respondents from diverse fields of expertise on average rate a DP as important. The number of experts who rate an item as "hardly relevant", "not relevant", "relevant" or "very relevant" adds to the overall impression of the value of a DP. With a heterogeneous group of experts, we did not aim for consensus, but in our view, DPs which most people think will have an effect are 
most promising. Items which were rated in the first round with a mean lower than 3 were considered to be valuable and left unchanged or adapted very slightly. These items were not included in the second round or, if they were, it was only to elicit feedback about the small revisions in the wording. One DP with a mean of 2.9 (DP 13) was not included. An asterisk in Table 1 indicates which items are involved. After the first round three principles were deleted (not reported on). In the second round all other items were presented anew in a reworded form and three new DPs were added, based on the feedback of the experts and in Table 1 indicated by a minus. Furthermore we extended our definition of a learning community and sent this to them. This statement was necessary because in comments the experts indicated that the wording of some items made them think that we had task-oriented teams in mind. Because no standard cut-off points exist for Delphi studies we formulated them ourselves: a DP with mean of three or larger was considered to be relevant; a DP with a mean smaller than 2.5 was considered not to be relevant. Next, we analyzed the comments of the respondents in order to find arguments for their rating. An updated literature search was performed on the DPs ranking high in the Delphi study, using the central theme of the DPs as keywords, to underpin the theoretical support for these DPs. The group discussion was analyzed using audio recordings of the subgroup discussions and notes taken by the first author during the meeting. The audio recordings were fully transcribed and strategies from the transcriptions were clustered and summarized.

\section{Results}

Formulating and Confirmation of DPs

Our literature study resulted in 28 DPs, presented in Table 1. In this table all DPs are included, in the order used during the first round when applicable, with the sources they have been derived from and details of whether they were asked anew in the second round.

In Table 2 the DPs are mentioned with their mean and the number of experts rating "not relevant", "hardly relevant", "relevant" or "very relevant". Of the principles, thirteen were found to be (very) relevant (indicated with an A), indicated by a mean $\geq 3$. DPs on which fewer experts were of the opinion that these DPs are "relevant" or "very relevant" (mean $<3$ ) are indicated by a B and a C, including the rating they received.

The items depicted in Table 2 with a B indication constitute a list of items on which the experts had different opinions (some experts rate them "hardly relevant" or "not relevant", others rate them "very relevant" or "relevant") and which are therefore hard to interpret on these quantitative data alone. For example, four experts rate an item (DP 11) like "Members strive for a balance between benefiting and contributing, not only participating in discussions but also in taking up small responsibilities like looking up literature in between meetings" as very relevant but three experts answer "Not relevant". In Table 2 four DPs (DP 15, DP 6, DP 24 and DP 23) are mentioned, on which most experts were of the opinion that these principles were not relevant for stimulating or supporting CRWB. 
Table 1 Overview of all DPs developed, which were part of the questionnaire, and the literature they are based on

Derived from

$1 *$ First time members of the community start

(Zarb 2006; ten Dam and Volman 2004) with observing several discussions without participating in order to get acquainted with the kind of discussions going on

2 During a meeting participants start with cases they feel comfortable with and later on continue with more challenging cases

3 First time members are invited to attend an information meeting to give an idea about the way cases are being discussed within the community

4 Members exchange views on how they struggled with certain cases

$5 *$ Members within the community discuss about cases selected from their own practices

6 People having a connection to the case start with a discussion but they stimulate quiet members and outsiders to participate as well

7 * Participants evaluate the quality of their discussions

8 * Participants encourage one another in being critical evaluators who try to prevent groupthink

9 Participants model for each other a critical and exploratory discussion style

10 Participants take up functional roles like facilitator, "devil's advocate" etc.

11 Members strive for a balance between benefiting and contributing, not only participating in discussions but also in taking up small responsibilities like looking up literature in between meetings

12 Participants take notice of different perspectives in the discussion but do not strive for unanimity

13 * Participants spend time to discuss different perspectives on every case

14 Members take time between (online and face-to-face) meetings to allow for reflection on the discussions

15 In time members participate in discussions with different parts of the community and compare discussion styles

16 Members find a meeting frequency (online or face-to-face) that allows them to combine participation in community with other obligations in life and work

(Bandura 1997)

(Watson and Hewett 2006; Zarb 2006)

(Jarvenpaa and Leidner 1999).

(Ashford et al. 2003; Groopman 2007)

(Hammond 1999)

(Janssen et al. 2007; Veerman 2000)

(Dron 2007; Janis 1982)

(Bandura 1997; ten Dam and Volman 2004)

(Kirschner et al. 2004; Miika and Leena 2002).

(McLure Wasko and Faraj 2000)

(Dron 2007; Janis 1982; Hmelo-Silver and Barrows 2008; Janssen et al. 2007; Veerman 2000; Cruz et al. 2006; Klocke 2007)

(Groopman 2007)

(Rushmer et al. 2004)

(Wenger 1998)

(Green and Ruff 2005) 
Table 1 (continued)

Derived from

17 Members determine who may become a member of the community (and who not)

$18 *$ Members create a culture in which talking about mistakes is allowed

19 Members meet face-to-face as often as they think necessary for establishing a safe group environment

$20 *$ Members ensure commitment within the community

$21 *$ Participants who want to explore a case in depth have the chance to discuss separately in a subgroup (and report their findings to the plenary group)

22 Members seek diversity in their group, especially in expertise, to achieve different points of view in the discussion

23 Members inform themselves about the reasons why other members in the group choose to participate

24 Participants consult people who have not participated in the discussion after a meeting and report back on this to the other participants

25 Members consult literature for additional evidence on the case to incorporate these findings in their discussions

26 - Members mark good examples of CRWB

27 - Participants pay attention to group cohesion but not at all cost

28 - First time members of the community are invited to attend a technical training
(Webber 2008)

(Van Woerkom 2003; Van Woerkom and Croon 2008; Harteis et al. 2008)

(Lockhorst 2004)

(Wenger et al. 2002; O'Donnell and O'Kelly 1994)

(Zarb 2006)

(Dron 2007; Shaw and Barrett-Power 1998; Hackman et al. 2008; Jehn et al. 1999; Lockhorst 2004)

(Berlanga et al. 2008; Hackman et al. 2008)

(Janis 1982; Kester et al. 2007; Van Rosmalen et al. 2006)

(Preece 2000; Sackett et al. 1996; Benbasat and Lim 2000)

(Bandura 1997; ten Dam and Volman 2004)

(Janis 1982; Janssen et al. 2007; Veerman 2000; Casey-Campbell and Martens 2009)

(Preece 2000; Hammond 1999)

Asterisk (*) means that items were rated in the first round only; Minus (-) means that items were rated in the second round only

Explaining the rationale for their score on relevance, the Delphi participants sometimes added conditions under which they thought that their answers hold true, as in case of the principle about the necessity of group norms for exploratory discussions (reworded in the second round as "Participants model for each other a critical and exploratory discussion style", DP 9): "I only agree with this, as long as they are shared by the members". Rarely did respondents mention what evidence supported their estimation of the relevance, with one exception: (DP 15), on participating in discussions with different parts of the community, "Members participate in different communities because that is the way their identities grow and become richer (according to social theory of learning)". Sometimes the comment field was made use of to explain why the option "unknown to me" was chosen, for instance that they based their answer on participants' experience in formal learning 
E. de Groot et al.

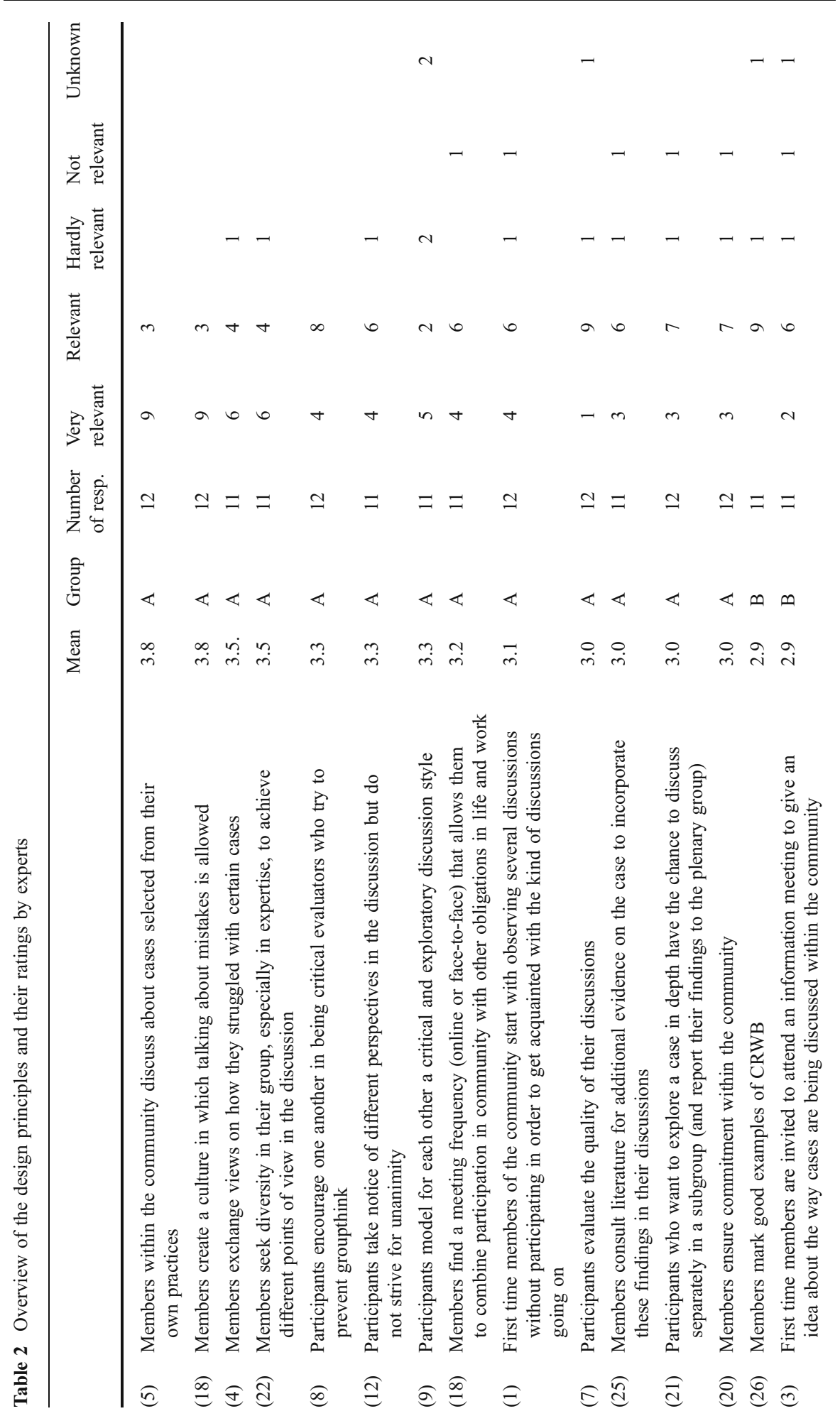




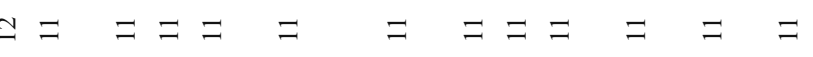

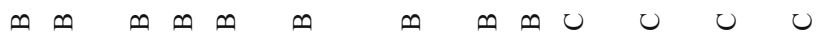

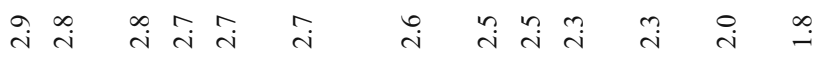

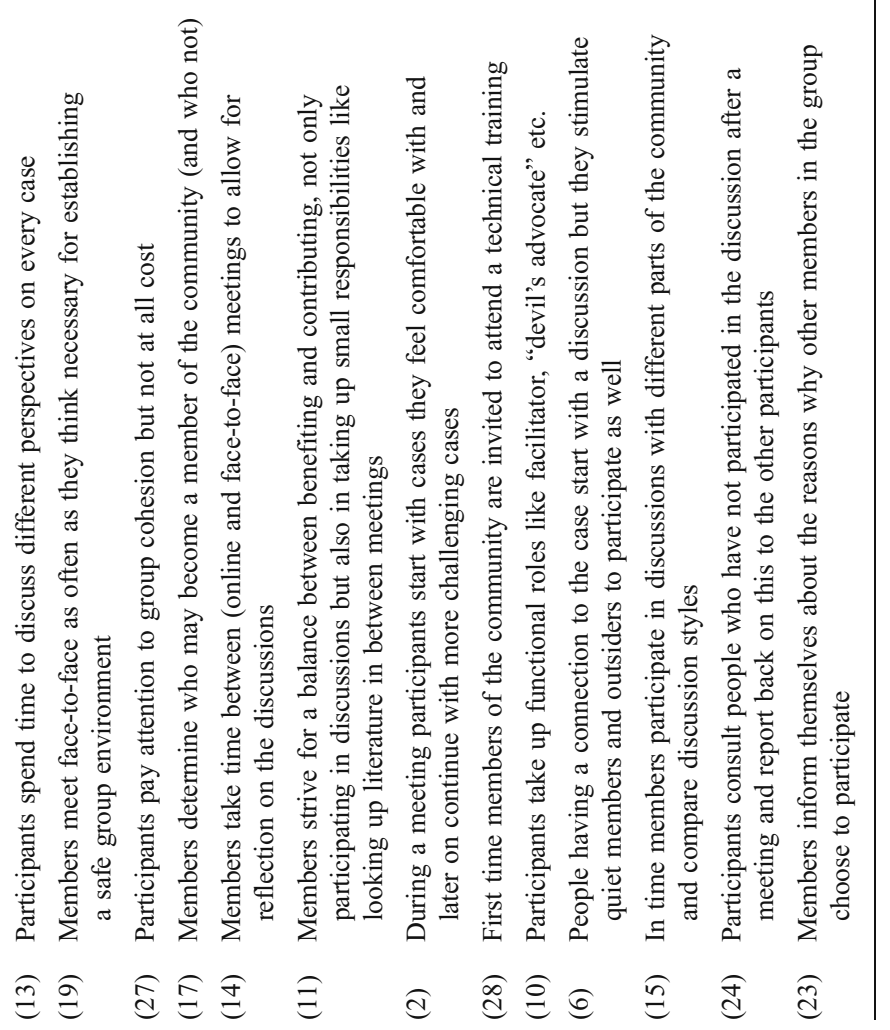


situations, not knowing if it could be extrapolated to informal learning communities. Sometimes suggestions were given for actual implementation, such as (DP 7, on the necessity of evaluating the discussion): "don't overdo it". These data show that from the 28 DPs derived from the literature, 13 DPs were considered important by the experts.

\section{Implementation of DPs}

Our third research question was on exploring strategies for implementation of the DPs, and subsequently on developing specific interventions. Several suggestions for implementation already appeared in the Delphi rounds. First suggestions at the level of technical tools were given, such as providing members with a personal log page where members of the community can formulate their own reflections without having to show them to the other members straightaway. Secondly, the strategy of modelling, by members from within the learning community, was brought forward. Thirdly, policies were proposed for use within the community, like an active invitation policy in combination with open subscription. Fourthly, organizing feedback on group functioning was thought to be helpful, for instance by using a "community barometer" (Coenders 2008). Organizing activities that members will value highly is mentioned as another intervention. Finally, employing a facilitator who performs the interventions mentioned in the other themes was judged most often as being important.

The exploration on implementation was taken further in the expert discussion meeting. From the DPs that were presented to them, participants endorsed especially the principles about challenging, authentic cases. Regarding implementation of these principles they indicated that offering cases in advance of the virtual or face-to-face meeting could help to get more of these challenging cases on the agenda. Cases could be used as a mechanism to form subgroups as well: people subscribe to a case they are interested in, getting people on board with the same topic-driven interest.

Referring to implementation of the DPs in general, the experts were unanimous in stressing the importance of finding a moderator from within the group, taking care that he or she is respected within the field and paying attention to his or her development as facilitator for the discussion. Furthermore, when planning blended or entirely virtual communities it is essential to ensure sufficient technical support. As a general rule the experts stressed the need of psychological safety. They thought it most important to focus first on those activities that contribute to building trust, in order to ensure sufficient participation (an issue in online environments mainly), trying to implement the principles directed at the quality of the discussion through increased CRWB later. Therefore DPs aiming at increased participation were seen as highly relevant to implement. Planning activities also depends on the developmental phase of the community: for example, a moderator may be more important at the start of a community and less important later on.

The experts differed in their views concerning the necessity of participants bringing in cases from their own practices anonymously. On the one hand bringing in cases anonymously might help to bring cases involving a mistake to the surface, thus building psychological safety. On the other hand this might make it less personal. In our further studies we will report about the effectiveness of some of the strategies, activities and tools suggested for the DPs scoring high in the Delphi study, 
having implemented them in the context of our aim to support work-related learning of autonomous professionals.

\section{Conclusions and Discussion}

A set of 28 DPs, acting as social affordances for CRWB within blended learning communities with autonomous professionals as members was abstracted from the literature, depicted in Table 1. Our results from the Delphi study lead to the conclusion that thirteen DPs are viewed as important by a diverse group of experts in the fields of e-learning, knowledge management and communities. Our findings mean that experts find the following important: "authenticity of the topics to be discussed", "openness about mistakes", "members seek diversity in their group, especially in expertise, to achieve different points of view in the discussion" and "exchange views on how they struggled with certain cases". When thinking about the support for learning communities of professionals these principles seem worthwhile to test in real life situations. Whether all these DPs are needed at the same time is uncertain, and a DP on cases from their own practice might, for example, be not easy to combine with a DP on openness about mistakes in the circumstances when a group has just started. Perhaps (see below), more knowledge about the mechanisms intermediating the effect of a DP might help to select a subset of principles. Similar lessons could be drawn from the group marked with a C. Although these principles were derived from literature, according to the experts these will not stimulate the community to become more critically reflective. For another eleven items (marked with a B in Table 2) experts within our group hold different opinions. Possibly these principles are more interesting from a theoretical point of view: what in the theoretical background of experts is causing these differences in opinion? Being aware of differences in opinions brought forward by experts might help to remain critically reflective on DPs which are derived from the literature (Coates 1975). An example of this is a DP on benefiting and contributing (DP 11), which four experts find "very relevant", three experts "relevant" but one expert thinks is "hardly relevant" and three experts think is "not relevant". A DP that deserves further attention as well is on knowing participants' background (DP 23), which eight experts consider to be hardly or not important for CRWB; as one of these experts stated in his/her comment, "it may also lead to presumptions". In practice this principle is confusing, because when diversity of expertise is seen as relevant (DP 22) it might be expected that, in order to utilize this diversity, members need to know more about the expertise of others. Hmelo-Silver (2009) suggested that identifying the knowledge necessary for a specific discussion is a way to design group diversity. Comparably, in field work attention needs to be paid to the item on consultation of others (DP 24). Experts in the Delphi study consider consulting others outside the group of participants of a group discussion to be hardly or not relevant for CRWB. One of the experts made it clear: he/she remarked, "it is always good to use knowledge of people outside your group, however, it depends how this knowledge is used, whether it supports CRWB in the sense of bringing 'fresh, other information sources in the discussion' or whether it blocks this behaviour, in the sense of "others say"'. In the second round two experts further stated that diversity of 
the group could be related to this principle "if the group is diverse [...], this [consultation of others, outside the group] doesn't have to be necessary".

On the question of what strategies an external organization could employ to realize the DPs in blended learning communities, with autonomous professionals as members, the discussion meeting highlighted the importance of psychological safety and sufficient technical support, before striving for CRWB. The participants did agree on the importance of challenging cases and the need for an internal moderator. With regard to the online environment they agreed on getting participation first, because even in formal educational settings students did not use these tools unless they were specifically directed to do so (Belland et al. 2008). In our opinion, some suggestions which could be useful in a formal educational setting raise questions when it comes to their applicability in informal learning in communities and need to be tested in practice. One of these questions is: how can participants be seduced to make full use of the possibilities of the online environment? For example: putting up a schedule for participants to give them the opportunity to make appointments for face-to-face meetings is easy; making them use it is presumably less easy. Specific behaviour is influenced heavily by the environment in which the day-to-day work of practitioners takes place. Their motivation and capability for CRWB is not changed easily just by participating in a learning community, not even when behaviour such as regularly evaluating their discussions is envisioned as social affordance. In bringing professionals to more CRWB in their interaction, organizations will have to admit that strategies with specific, concrete and definitive outcomes will be limited (Wenger et al. 2002). This is especially true for autonomous professionals for whom, in contrast to teams within an organization, parallel policies for culture change cannot be introduced.

Our study describes the first steps in a design based research. Studies using this research method are increasingly interested in the mechanism behind effects of interventions (Van Aken 2004). When thinking about affordances for behaviour, implying behavioural change, it is relevant to explore how these processes of change occur, so a model of behavioural change could be relevant. A well-known model for behavioural change, adopted in management and marketing literature (Poiesz 1994; Poiesz 1999; Siemsen et al. 2008) and literature on knowledge sharing (Huysman and Wulf 2004), is the Motivation-Opportunity-Ability (MOA) framework, which closely resembles the Triade model (Poiesz 1994; Poiesz 1999). Members change their behaviour when they feel (more) motivated (intrinsically or extrinsically) to do so, and have the opportunity and ability to act accordingly. The Triade model will be relevant for strategies for implementation because the constraining factor among these three variables (motivation, opportunity and ability) determines behaviour (Siemsen et al. 2008). For instance, implementing a DP that has an effect on opportunity will not result in more CRWB when motivation is constrained. Further elaboration on our results with considerations about mechanisms in mind is appropriate, because insight in mechanisms will add to the theoretical value of design based research. In addition, we think that this model can help to bridge the gap between theoretical ideas about DPs addressing a change in behaviour, and actual implementation which has been the focus in research question three. The Triade model stresses the need for scaffolding participants' motivation, opportunity and capability as well as keeping these in balance. 
A second issue that could improve and add to the usefulness of our study's results is about phases of development of a community. Combining data from the Delphi study and the discussion meeting illustrated that, especially for the strategies to realize specific DPs, one may have to pay attention in field testing to the phase of development. A strategy might be indispensable in the beginning of a community but not later on. In the Delphi it was mentioned, for instance, that "When a community of practice gains experience this role may become less important" [on the role of the moderator]. Another example of a DP differing in importance depending on the phase of development relates to discussing participants' own cases, perceived as being highly relevant for CRWB. In the beginning participants may not be inclined to bring in cases in which they have made mistakes. On that ground it has been proposed in the discussion meeting that participants should bring in their cases anonymously, though this makes the discussion less personal. As trust may grow in time during the development of a community, the strategy of bringing in anonymous cases in the sense of "challenging cases" can be helpful in preparing the case holder to talk more openly about his or her mistakes (Harteis et al. 2008). A third example of a DP dependent on the phase of development is commitment, on whose importance the experts agreed. We envision that commitment, like trust, grows in time. Guarding group diversity of expertise would be a way of preventing the drawback of commitment, which is that groups who put solidarity first are more prone to groupthink (Janis 1982), and "commitment" can come close in meaning to "solidarity". Too much homogeneity in group composition will be disadvantageous for CRWB. The tension between homogeneity and heterogeneity has been described before (Lockhorst 2004). As one of the members in the discussion meeting stated, "An ideal design might start with homogeneity and add new members to it in time to make it more heterogeneous."

\section{Comments on the Approach}

Our approach leaves room for improvement. The Delphi method in general has been criticized (Jones and Hunter 1995; Webler et al. 1991; Steinert 2009) due to bias in the selection of participants and difficulties in reliability. Moreover, very diverse approaches are all labelled "Delphi" (Coates 1975). An approach such as the one we made use of (and which is often used), is perhaps better not labelled as a Delphi method at all, to avoid confusion about the goal of the methodology. A label like "rating device" would reflect the purpose better (Thompson 2009). We argue that ratings and making differences in opinions explicit are valuable research activities, and we agree with Sharkey and Sharples (2001) that Delphi results are useful, as long as these results are not interpreted as "the correct answer" without further testing. Another limitation of our study could be found because, for feasibility reasons, we did not approach a much larger group, which would have improved our data. Furthermore, in our Delphi study, the experts did not pay much attention to the support for their opinions, which did not allow us to assess whether their opinions are based foremost on strong personal beliefs or on their knowledge of the field. Despite these limitations, we think that our results are worthwhile from the perspective that we made use of Delphi primarily as an exploratory technique aimed at getting guidance from experts' opinions for future field work, and for getting 
multi-disciplinary perspectives on our topic of interest. The Delphi study gives an indication of the importance of our DPs but they will have to be tested against observed data in a specific context: in our situation that of veterinarians in learning communities.

\section{Future Research and Implications}

Apart from future research involving ongoing refinements in wording, studies to acquire more insight into the relation between the DPs and the phase of development of a community, as well as in the mechanism behind effects, would be useful. Furthermore the context and conditions under which a DP elicits CRWB-like or CRWB-supporting interactive behaviour deserves additional exploration. Design based research finds its root in discontent about the applicability of research results; testing findings in real life contexts recognizes the limits of design. In future research we ourselves will test a combination of DPs, concentrating on veterinary professionals' learning communities in diverse developmental phases. The findings are relevant for other professionals as well, especially for people within organizations, who aim to set up or analyze learning communities for professionals connected with their organization (like universities supporting communities for their alumni as part of their continuing education offerings). The design principles are relevant when they set up learning communities with the purpose of facilitating CRWB, and the strategies as well as the discussion about those strategies, for instance on the importance of communities' development phase and of the role of a moderator, help with implementation of design principles. The implications of this research are to sharpen thinking about what is designable and what is not, and about the need to look at sources from diverse fields.

Open Access This article is distributed under the terms of the Creative Commons Attribution Noncommercial License which permits any noncommercial use, distribution, and reproduction in any medium, provided the original author(s) and source are credited.

\section{References}

Akkerman, S., Petter, C., \& De Laat, M. (2008). Organising communities-of-practice: facilitating emergence. Journal of Workplace Learning, 20(6), 383-399.

Ashford, S. J., Blatt, R., \& VandeWalle, D. (2003). Reflections on the looking glass: a review of research on feedback-seeking behavior organizations. Journal of Management, 29(6), 773-799.

Baguley, M., \& Brown, A. (2009). Critical friends: an investigation of shared narrative practice between education and nursing graduates. Teaching in Higher Education, 14(2), 195-207.

Bandura, A. (1997). Self-efficacy: The exercise of control. New York: Freeman and Company.

Belland, B., Glazewski, K., \& Richardson, J. (2008). A scaffolding framework to support the construction of evidence-based arguments among middle school students. Educational Technology Research and Development, 56(4), 401-422.

Benbasat, I., \& Lim, J. (2000). Information technology support for debiasing group judgments: an empirical evaluation. Organizational Behaviour and Human Decision Processes, 83(1), 167-183.

Bennett, N. L., Davis, D. A., Easterling, W. E., Jr., Friedmann, P., Green, J. S., Koeppen, N. M., et al. (2000). Continuing medical education: a new vision of the professional development of physicians. Academic Medicine, 75(12), 1167-1172. 
Berlanga, A. J., Brouns, F., Bitter-Rijpkema, M., \& Sloep, P. (2008). On the importance of personal profiles to enhance social interaction in learning networks. In P. Kommers (Ed.), Proceedings of the Web Based Communities Conference (WEBC 2008) (pp. 55-62). Amsterdam: IADIS.

Billett, S. (2001). Learning in the workplace. Crows Nest: Allen \& Unwin.

Billett, S., \& Pavlova, M. (2005). Learning through working life: self and individuals' agentic action. International Journal of Lifelong Education, 24(3), 195-211.

Brookfield, S. (2009). The concept of critical reflection: promises and contradictions. European Journal of Social Work, 12(3), 293-304.

Brown, A. L., \& Campione, J. C. (1996). Psychological theory and the design of innovative learning environments. In L. Schlauble \& R. Glaser (Eds.), Innovations in learning (pp. 289-325). Mahwah: Lawrence Erlbaum Associated.

Casey-Campbell, M., \& Martens, M. L. (2009). Sticking it all together: a critical assessment of the group cohesion-performance literature. International Journal of Management Reviews, 11(2), 223-246.

Coates, J. F. (1975). In defense of Delphi: a review of Delphi assessment, expert opinion, forecasting, and group process by H. Sackman. Technological Forecasting and Social Change, 7(2), 193-194.

Coenders, M. (2008). Learning architecture. Doctoral Thesis. Delft: Uitgeverij Eburon.

Cox, A. (2005). What are communities of practice? A comparative review of four seminal works. Journal of Information Science, 31(6), 527-540.

Cruz, M., Henningsen, D., Henningsen, M., \& Eden, J. (2006). Examining the symptoms of groupthink and retrospective sensemaking. Small Group Research, 37(1), 36-64.

Davis, D., O’Brien, M. A. T., Freemantle, N., Wolf, F. M., Mazmanian, P., \& Taylor-Vaisey, A. (1999). Impact of formal continuing medical education: do conferences, workshops, rounds, and other traditional continuing education activities change physician behavior or health care outcomes? Journal of the American Medical Association, 282(9), 867-874.

Delany, C., \& Watkin, D. (2009). A study of critical reflection in health professional education: 'learning where others are coming from'. Advances in Health Sciences Education, 14(3), 411-429.

Dron, J. (2007). Designing the undesignable: social software and control. Educational Technology \& Society, 10(3), 60-71.

Earl, L. M., \& Timperley, H. (Eds.). (2009). Professional learning conversations. Milton Keynes: Springer.

Eraut, M. (2004). Informal learning in the workplace. Studies in Continuing Education, 26(2), 247-273.

Ferguson, K. J., Wolter, E. M., Yarbrough, D. B., Carline, J. D., \& Krupat, E. (2009). Defining and describing medical learning communities: results of a national survey. Academic Medicine, 84(11), 1549-1556.

Fook, J., \& Askeland, G. A. (2007). Challenges of critical reflection: 'nothing ventured, nothing gained'. Social Work Education, 26(5), 520-533.

Gambrill, E. S. (1990). Critical thinking in clinical practice: improving the accuracy of judgments and decisions about clients. San Francisco: Jossey-Bass.

Gartmeier, M., Bauer, J., Gruber, H., \& Heid, H. (2008). Negative knowledge: understanding professional learning and expertise. Vocations and Learning, 1(2), 87-103.

Gaver, W. W. (1996). Situating action II: affordances for interaction-The social is material for design. Ecological Psychology, 8(2), 111-129.

Gravemeijer, K., \& Cobb, P. (2006). Design research from a learning design perspective. In J. Van den Akker, K. Gravemeijer, S. McKenny, \& N. Nieveen (Eds.), Educational design research (pp. 17-51). New York: Routledge.

Green, M. L., \& Ruff, T. R. (2005). Why do residents fail to answer their clinical questions? A qualitative study of barriers to practicing evidence-based medicine. Academic Medicine, 80(2), 176-182.

Groopman, J. E. (2007). How doctors think. New York: Houghton Mifflin Company.

Hackman, J., Woolley, A., Gerbasi, M., Chabris, C., \& Kosslyn, S. (2008). Bringing in the experts: how team composition and collaborative planning jointly shape analytic effectiveness. Small Group Research, 39(3), 352-371.

Hakkarainen, K., Palonen, T., Paavola, S., \& Lehtinen, E. (2004). Communities of networked expertise. Amsterdam: Elsevier.

Hammond, M. (1999). Issues associated with participation in on line forums-The case of the communicative learner. Education and Information Technologies, 4(4), 353-367.

Hagler, D. A., \& Brem, S. K. (2008). Reaching agreement: the structure \& pragmatics of critical care nurses' informal argument. Contemporary Educational Psychology, 33(3), 403-424.

Harteis, C., Bauer, J., \& Gruber, H. (2008). The culture of learning from mistakes: how employees handle mistakes in everyday work. International Journal of Educational Research, 47(4), 223-231. 
Hattie, J., \& Timperley, H. (2007). The power of feedback. Review of Educational Research, 77(1), 81112 .

Hmelo-Silver, C. E. (2009). Facilitating social knowledge construction in communities of learners: Are we there yet (and how will we know)? Key-note at the 13th Biennial Conference of the European Association for Research on Learning and Instruction. Fostering Communities of Learners, Amsterdam.

Hmelo-Silver, C. E., \& Barrows, H. S. (2008). Facilitating collaborative knowledge building. Cognition and Instruction, 26(1), 48-94.

Hodkinson, P., Biesta, G., \& James, D. (2008). Understanding learning culturally: overcoming the dualism between social and individual views of learning. Vocations and Learning, 1(1), 27-47.

Huysman, M., \& Wulf, V. (2004). Social capital and information technology. Cambridge: MIT.

Janis, I. L. (1982). Groupthink: psychological studies of policy decisions and fiascoes. Boston: Houghton Mifflin Company.

Janssen, J., Erkens, G., Kanselaar, G., \& Jaspers, J. (2007). Visualization of participation: does it contribute to successful computer-supported collaborative learning? Computers \& Education, 49(4), 1037-1065.

Jarvenpaa, S. L., \& Leidner, D. E. (1999). Communication and trust in global virtual teams. Organization Science, 10(6), 791-815.

Jehn, K. A., Northcraft, G. B., \& Neale, M. A. (1999). Why differences make a difference: a field study of diversity, conflict, and performance in workgroups. Administrative Science Quarterly, 44(4), 741-763.

Johnsson, M. C., \& Boud, D. (2010). Towards an emerging view of learning work. International Journal of Lifelong Education, 29(3), 359-372.

Jones, J., \& Hunter, D. (1995). Consensus methods for medical and health services research. British Medical Journal, 311(7001), 376-380.

Kamin, C., O’Sullivan, P., Deterding, R., \& Younger, M. (2003). A comparison of critical thinking in groups of third-year medical students in text, video, and virtual pbl case modalities. Academic Medicine, 78(2), 204-211.

Karvinen-Niinikoski, S. (2009). Promises and pressures of critical reflection for social work coping in change. European Journal of Social Work, 12(3), 333-348.

Kester, L., van Rosmalen, P., Sloep, P., Brouns, F., Koné, M., \& Koper, R. (2007). Matchmaking in learning networks: bringing learners together for knowledge sharing. Interactive Learning Environments, 15(2), 117-126.

Kim, S., Farber, S., Kolko, B. E., Kim, W., Ellsbury, K. E., \& Greer, T. (2006). Faculty and student participation in online discussions of palliative care scenarios. Family Medicine, 38(7), 494-499.

King, P. M., \& Kitchener, K. S. (2004). Reflective judgment: theory and research on the development of epistemic assumptions through adulthood. Educational Psychologist, 39(1), 5-18.

Kirschner, P., Strijbos, J., Kreijns, K., \& Beers, P. J. (2004). Designing electronic collaborative learning environments. Educational Technology Research and Development, 52(3), 47-66.

Klocke, U. (2007). How to improve decision making in small groups: effects of dissent and training interventions. Small Group Research, 38(3), 437-468.

Koper, R., Giesbers, B., van Rosmalen, P., Sloep, P., van Bruggen, J., Tattersall, C., et al. (2005). A design model for lifelong learning networks. Interactive Learning Environments, 13(1-2), 71-92.

Li, L. C., Grimshaw, J. M., Nielsen, C., Judd, M., Coyte, P. C., \& Graham, I. D. (2009). Evolution of Wenger's concept of community of practice. Implementation Science, 4(11).

Lockhorst, D. (2004). Design principles for a CSCL environment in teacher training. Unpublished doctoral dissertation, Utrecht University, the Netherlands.

Mann, K., Gordon, J., \& MacLeod, A. (2007). Reflection and reflective practice in health professions education: a systematic review. Advances in Health Sciences Education, 14(4), 595-621.

Maudsley, G., \& Strivens, J. (2000). Promoting professional knowledge, experiential learning and critical thinking for medical students. Medical Education, 34(7), 535-544.

McLure Wasko, M., \& Faraj, S. (2000). "it is what one does": why people participate and help others in electronic communities of practice. Journal of Strategic Information Systems, 9(2-3), 155-173.

Mezirow, J. (1990). How critical reflection triggers transformative learning. In J. Mezirow et al. (Eds.), Fostering critical reflection in adulthood. A guide to transformative and emancipatory learning (pp. 1-20). San Francisco: Jossey-Bass.

Mezirow, J. (1998). On critical reflection. Adult Education Quarterly, 48(3), 185-198.

Miika, M., \& Leena, L. (2002). Quality of students' argumentation by email. Learning Environments Research, 5(1), 99-123. 
Moore, D. A., Klingborg, D. J., Brenner, J. S., \& Gotz, A. A. (2000). Motivations for and barriers to engaging in continuing veterinary medical education. Journal of the American Veterinary Medical Association, 217(7), 1001-1005.

O’Donnell, A. M., \& O'Kelly, J. (1994). Learning from peers: beyond the rhetoric of positive results. Educational Psychology Review, 6(4), 321-349.

Oxman, A. D., Thomson, M. A., Davis, D. A., \& Haynes, B. (1995). No magic bullets: a systematic review of 102 trials of interventions to improve professional practice. Canadian Medical Association Journal, 153(10), 1423-1431.

Parboosingh, J. T. (2002). Physician communities of practice: where learning and practice are inseparable. The Journal of Continuing Education in the Health Professions, 22(4), 230-236.

Pinelle, D., \& Gutwin, C. (2006). Loose coupling and healthcare organizations: deployment strategies for groupware. Computer Supported Cooperative Work: CSCW: An International Journal, 15(5-6), 537-572.

Poiesz, T. P. B. (1994). The assessment of communication quality-theory and application of the Triad model. Proceedings of the 46th Marketing Research Congress of the European Society for Opinion and Market Research. The many faces of quality, now and in the future (pp. 137-159). Kopenhagen.

Poiesz, T. P. B. (1999). Gedragsmanagement. Wormer: Inmerc.

Preece, J. (2000). Online communities: Designing usability, supporting sociability. Chichester: John Wiley \& Sons, Ltd.

Price, D. W., \& Felix, K. G. (2008). Journal clubs and case conferences: from academic tradition to communities of practice. Journal of Continuing Education in the Health Professions, 28(3), 123-130.

Rushmer, R., Kelly, D., Lough, M., Wilkinson, J. E., \& Davies, H. T. O. (2004). Introducing the learning practice-III. Leadership, empowerment, protected time and reflective practice as core contextual conditions. Journal of Evaluation in Clinical Practice, 10(3), 399-405.

Sackett, D. L., Rosenberg, W. M. C., Gray, J. A. M., Haynes, R. B., \& Richardson, W. S. (1996). Evidence based medicine: what it is and what it isn't. It's about integrating individual clinical expertise and the best external evidence. British Medical Journal, 312(7023), 71-72.

Schön, D. A. (1991). The reflective practitioner: How professionals think in action. Farnham: Ashgate.

Sharkey, S. B., \& Sharples, A. Y. (2001). An approach to consensus building using the Delphi technique: developing a learning resource in mental health. Nurse Education Today, 21(5), 398-408.

Shaw, J. B., \& Barrett-Power, E. (1998). The effects of diversity on small work group processes and performance. Human Relations, 51(10), 1307-1325.

Siemsen, E., Roth, A. V., \& Balasubramanian, S. (2008). How motivation, opportunity, and ability drive knowledge sharing: the constraining-factor model. Journal of Operations Management, 26(3), 426445 .

Simons, P. R. J., \& Ruijters, M. C. P. (2004). Learning professionals: Towards an integrated model. In H. P. A. Boshuizen, R. Bromme, \& H. Gruber (Eds.), Professional learning: Gaps and transitions on the way from novice to expert (pp. 207-229). Dordrecht: Kluwer Academic.

Steinert, M. (2009). A dissensus based online Delphi approach: an explorative research tool. Technological Forecasting and Social Change, 76(3), 291-300.

Swanwick, T. (2005). Informal learning in postgraduate medical education: from cognitivism to 'culturism'. Medical Education, 39(8), 859-865.

Ten Dam, G., \& Volman, M. (2004). Critical thinking as a citizenship competence: teaching strategies. Learning and Instruction, 14(4), 359-379.

Thompson, M. (2009). Considering the implication of variations within Delphi research. Family Practice, $26(5), 420-424$.

Tigelaar, D. E. H., Dolmans, D. H. J. M., Meijer, P. C., De Grave, W. S., \& Van Der Vleuten, C. P. M. (2008). Teachers' interactions and their collaborative reflection processes during peer meetings. Advances in Health Sciences Education, 13(3), 289-308.

Van Aken, J. E. (2004). Management research based on the paradigm of the design sciences: the quest for field-tested and grounded technological rules. Journal of Management Studies, 41(2), 219-246.

Van Rosmalen, P., Sloep, P., Brouns, F., Kester, L., Koné, M., \& Koper, R. (2006). Knowledge matchmaking in learning networks: alleviating the tutor load by mutually connecting Learning Network users. British Journal of Educational Technology, 37(6), 881-895.

Van Woerkom, M. (2003). Critical reflection at work. Unpublished doctoral dissertation, Twente University, the Netherlands.

Van Woerkom, M., \& Croon, M. (2008). Operationalising critically reflective work behaviour. Personnel Review, 37(3), 317-331.

Veerman, A. L. (2000). Computer-supported collaborative learning through argumentation. Unpublished doctoral dissertation, Universiteit Utrecht, the Netherlands. 
Watson, S., \& Hewett, K. (2006). A multi-theoretical model of knowledge transfer in organizations: determinants of knowledge contribution and knowledge reuse. Journal of Management Studies, 43(2), $141-173$.

Webber, S. (2008). Development of cognitive and affective trust in teams: a longitudinal study. Small Group Research, 39(6), 746-769.

Webler, T., Levine, D., Rakel, H., \& Renn, O. (1991). A novel approach to reducing uncertainty: the group Delphi. Technological Forecasting and Social Change, 39(3), 253-263.

Wenger, E. (1998). Communities of practice: learning, meaning, and identity. Cambridge: Cambridge University Press.

Wenger, E., MacDermott, R., \& Snyder, W. M. (2002). Cultivating communities of practice: A guide to managing knowledge. Boston: Harvard Business School Press.

Wood, D. R. (2007). Professional learning communities: teachers, knowledge, and knowing. Theory into Practice, 46(4), 281-290.

Wright, J., \& Titchen, A. (2003). Critical companionship. Part 2: using the framework. Nursing Standard, $18(10), 33-38$.

Zarb, M. P. (2006). Modelling participation in virtual communities-of-practice. Retrieved on 1-4-2008 from http://www.mzarb.com

Esther de Groot is a $\mathrm{PhD}$ student and consultant at the faculty of Veterinary Medicine, Utrecht University, PO Box 80163, 3508 TD, The Netherlands E-mail: e.degroot@uu.nl. Her research interests include work-related learning, evidence based veterinary medicine, informal learning and e-learning.

Dr. B.A.M. van den Berg IVLOS Institute of Education, Utrecht University, PO Box 801273508 TC Utrecht, The Netherlands. E-mail B.A.M.vandenberg@uu.nl. Her research interests include peer-to-peer learning and work-related learning.

Dr. M.D. Endedijk IVLOS Institute of Education, Utrecht University, PO Box 801273508 TC Utrecht, The Netherlands. E-mail M.D.Endedijk@uu.nl. Her research interests include self-directed learning and learning of professionals.

Prof. P. van Beukelen DVM, $\mathrm{PhD}$, is a professor in quality improvement in veterinary medical education at the faculty of Veterinary Medicine, Utrecht University, PO Box 80163, 3508 TD, The Netherlands Email p.vanbeukelen@uu.nl. His research interests include quality assurance, faculty development, clinical reasoning, professional conduct and work-related learning.

Prof. dr. P.R.J. Simons IVLOS Institute of Education, Utrecht University, PO Box 801273508 TC Utrecht, The Netherlands. E-mail P.R.J.Simons@uu.nl. His research interests include, learning of professionals, computer-based learning and work-related learning. 